\title{
Article \\ Effects of Coating on the Dimensional Stability of Wood-Polymer Composites
}

\author{
Marouan Rejeb ${ }^{1}$, Ahmed Koubaa ${ }^{1, *} \mathbb{0}$, Fayez Elleuch ${ }^{1,2}$, François Godard ${ }^{1,3}$, Sébastien Migneault ${ }^{1}$, \\ Mohamed Khlif ${ }^{2}$ (D) and Hatem Mrad $^{3}$ \\ 1 Laboratoire de Biomatériaux, Université du Québec en Abitibi-Témiscamingue, Rouyn-Noranda, QC J9X 5E4, \\ Canada; marouan.rejeb@uqat.ca (M.R.); Fayez.elleuch@uqat.ca (F.E.); Francois.godard@uqat.ca (F.G.); \\ Sebastien.migneault@uqat.ca (S.M.) \\ 2 Laboratoire des Systèmes Électromécaniques (LASEM), École Nationale D'ingénieurs de Sfax, \\ Université de Sfax, Sfax 3038, Tunisia; khlifmohamed@yahoo.fr \\ 3 École de Génie, Université du Québec en Abitibi-Témiscamingue, Rouyn-Noranda, QC J9X 5E4, Canada; \\ Hatem.mrad@uqat.ca \\ * Correspondence: ahmed.koubaa@uqat.ca; Tel.: +1-819-762-0971 (ext. 2579)
}

check for updates

Citation: Rejeb, M.; Koubaa, A.; Elleuch, F.; Godard, F.; Migneault, S.; Khlif, M.; Mrad, H. Effects of Coating on the Dimensional Stability of Wood-Polymer Composites. Coatings 2021, 11, 711. https://doi.org/ 10.3390/coatings 11060711

Academic Editors:

Mariaenrica Frigione and

Salim Hiziroglu

Received: 7 March 2021

Accepted: 10 June 2021

Published: 13 June 2021

Publisher's Note: MDPI stays neutral with regard to jurisdictional claims in published maps and institutional affiliations.

Copyright: (c) 2021 by the authors. Licensee MDPI, Basel, Switzerland. This article is an open access article distributed under the terms and conditions of the Creative Commons Attribution (CC BY) license (https:// creativecommons.org/licenses/by/ $4.0 /)$.

\begin{abstract}
Wood polymer composites (WPC) are sensitive to moisture because of the hydrophilic nature of the wood fibers. The main objective of this study was to improve the dimensional stability of WPCs by coating. Polypropylene and polylactic acid were reinforced by three pulp fibers (kraft, thermomechanical (TMP), and chemothermomechanical (CTMP)) at three fiber contents (50,60, and $70 \% \mathrm{w} / \mathrm{w})$. The resulting WPCs were coated using two commercial coatings, epoxy and acrylic. Kraft fiber WPCs were less sensitive to moisture than TMP and CTMP WPCs. These differences were explained by the crystallinity of the kraft fibers and their better interfacial adhesion to the polymers. The epoxy coating proved to be more effective than the acrylic coating and significantly reduced the water absorption and the thickness swell for all formulations. Negative relationships between the contact angle and water absorption were obtained. These relationships depend on the fiber content and type, the matrix nature, and the coating.
\end{abstract}

Keywords: wood polymer biocomposites; dimensional stability; hydrophobicity; contact angle; water absorption; thickness swell

\section{Introduction}

Interest in composite materials has steadily increased in recent decades. Composites are materials that combine at least two distinct components, one being the matrix and the other the reinforcement, to take advantage of the characteristics of each component and create a material with improved performance [1,2]. Wood polymer composites (also called Wood Plastic Composites in the scientific literature, WPCs) consisting of lignocellulosic fiber, which could be very fine sawdust, a pulp fiber, or natural fiber, and a thermoplastic matrix are among the most attractive composites. WPC's global market size was estimated at USD 5.3 billion in 2019 and is expected to grow at a rate of 11.4\% over the 2020-2027 period [3]. Several polymers have been used as matrices; these include polyethylene (PE), polypropylene (PP), polyvinyl chloride (PVC), polystyrene (PS), and polylactic acid (PLA) [4-6]. For WPCs, wood is incorporated in short fibers, wood flour, paper fibers [7], or paper sludge [8]. Additives such as coupling agents, stabilizers, and lubricants are used to improve the matrix-fiber compatibility or processing [9].

WPCs are widely used in exterior and interior applications. Exterior uses, such as in humid environments, require good resistance to weathering and especially to water absorption and swelling. They are used in transportation, automotive, outdoor construction and decoration, and other fields because of their low water absorption and recyclability [10,11]. They have received significant interest from academia and industry due to their low environ- 
mental impact and economic benefits. However, several drawbacks, such as dimensional stability and thermal stability, are still to overcome before expanding future uses.

WPCs contain a hydrophobic matrix and a hydrophilic lignocellulosic fiber. Sensitivity to moisture is mainly due to the presence of hydroxyl groups from the lignocellulosic component. Their properties are closely related to their fiber content. Indeed, the fiber is the gateway for the entry and diffusion of water in the composite. This weight gain mainly corresponds to the hydrophilic fiber components, hemicelluloses, and cellulose [12-14].

On the other hand, lignin, the fiber hydrophobic component, absorbs less water than other wood components [15]. Two mechanisms can explain WPC water absorption. The first is porous natural fibers, which increase the WPC hydrophilicity and facilitate water diffusion. The second mechanism is due to the heterogeneity of the materials, which generates voids and cracks at the interface. It, therefore, favors the entry of water into the composite through capillary transport in high concentrations [16]. Increasing the fiber content leads to an increase in absorption. Indeed, high fiber content increases the probability of finding voids in the WPC where water can be stored [16]. Additionally, the fiber cell wall is hygroscopic and absorbs water [17]. Water in composites can exist in three regions: the wood cell lumen, the wood cell walls, and the gaps between the filler and matrix in the interface region [18]. Improving the fiber-matrix interfacial adhesion decreases the hydrophilic character of the wood and, thus, reduces the gap between the matrix and the filler, limiting the penetration of water into this space. The hydrophobic plastic protects from water to the composites by encapsulating the wood fibers thus, reducing water absorption.

Espert et al. [19] showed that the mechanical properties of PP-based WPCs are considerably affected by water absorption. Water-saturated samples show poor mechanical properties. In some cases, a low percentage of the coupling agent in the composite leads to improved water absorption resistance due to improved adhesion between the fiber and the polymer. Heinemann et al. [20] assumed a better interaction between PLA and natural fibers than between PP and natural fibers due to the hydrophilic nature of PLA.

Espert et al. [19] reported that water absorption by natural fibers/PP composites followed the kinetics of a Fickian diffusion process. The fiber content, the matrix type, and the temperature are the main controlling factors of the kinetics parameters when using the Arrhenius law.

Protective coatings improve WPC behavior for exterior uses. However, knowledge of the surface properties of the composite is essential for the development of a suitable coating system. Teng et al. [21] demonstrated that the contact angle of the surface of wood/polyethylene composites decreased. The surface's wettability improved after liquid oxidation and led to the formation of $-\mathrm{C}-\mathrm{O}-$ and $\mathrm{C}=\mathrm{O}$ functional groups on the treated surface, and the surface roughness increased. Thus, after treatment, the shear bond strength for the treated sample increased significantly.

The main objective of this work was to improve the WPC dimensional stability by co coating. This study investigated the effect of two commercial coatings on WPC water absorption, thickness swell, and contact angle. To our knowledge, no previous study investigated the impact of two different coatings on the dimensional stability of bio-based composites made with different matrices (PLA and PP), different pulp fibers, and high fiber contents. Novel aspects of this study include the production of bio-based composites with $100 \%$ renewable ingredients, including the coating. The production of high-fiber content (up to $70 \%$ ) bio-based composites with an injection process is novel and challenging, especially with renewable PLA matrices. Additionally, the study investigated the potential of bio-based coating to improve the WPC dimensional stability compared to a commercial nonrenewable coating such as chromic coatings. The latter is used to coat various materials, including polymers, metals, ceramics, and in different fields, including construction, automotive, and transportation, in which durability, corrosion resistance, and aesthetics are valued [22]. However, some environmental issues are raised concerning its impact on humans and the environment. Chromium can leach into the groundwater 
in its most soluble forms. Some plants may be affected in their germination or growth due to high chromium concentrations. Chromium is considered toxic to human health in some states after long-term exposure, but is not carcinogenic according to the Occupational Safety and Health Administration (OSHA) [23]. For chromium remediation, activated carbon and ion exchange filtration effectively control chromium contamination [24]. Controlled management of chrome-treated products at the end of service would limit their environmental impact.

\section{Materials and Methods}

\subsection{Materials}

Polypropylene (PP) (NexeoSolutions, The Woodlands, TX, USA) with a density of $0.903 \mathrm{~g} \mathrm{~cm}^{-3}$, and a $20 \mathrm{~g} / 10 \mathrm{~min}$ melt index, and polylactic acid (PLA) Ingeo 3001D (NatureWorks, Minnetonka, MN, USA) with a density of $1.24 \mathrm{~g} \mathrm{~cm}^{-3}$, melt flow rate of $22 \mathrm{~g} / 10 \mathrm{~min}$. Pulp fibers from three papermaking processes (kraft provided by Domtar Inc., Windsor, QC, Canada) thermomechanical (TMP) obtained from Resolu Amos (Amos, QC, Canada), and chemothermomechanical (CTMP) provided by the Université du Québec à Trois-Rivières (Trois-Rivières, QC, Canada) at three different fiber proportions (50, 60, and $70 \%$, weight basis) were used for WPC manufacturing. Pulps morphological and chemical properties are summarized in Table 1. STRUKTOL ${ }^{\circledR}$ TPW 113 from Struktol Company of America (Stow, OH, USA) was used as a coupling agent for the mixture of wood fibers and the PP matrix at a rate of $5 \%$ on a weight basis.

Table 1. Pulps morphological and chemical properties.

\begin{tabular}{cccc}
\hline Properties & TMP & CTMP & Kraft \\
\hline & \multicolumn{1}{c}{ Morphological properties } \\
\hline Length $(\mathrm{mm})$ & 0.48 & 0.57 & 0.78 \\
Diameter $(\mu \mathrm{m})$ & 23.7 & 23.4 & 22.6 \\
L/D & 20.25 & 24.36 & 34.51 \\
\hline \multicolumn{4}{c}{ Chemical composition } \\
\hline Cellulose $(\%)$ & $49.7(0.5)$ & $52.7(4.8)$ & $87.9(1.1)$ \\
Lignin $(\%)$ & $25.3(0.3)$ & $29.9(0.9)$ & $0.4(0.0)$ \\
Extractives $(\%)$ & $7.3(0.2)$ & $4.6(0.2)$ & $3.4(0.6)$ \\
\hline
\end{tabular}

Two commercial coatings were used: 1) Acrylic coating (ALIS Terrace Oil No. 579 from Livos, Proulxville, QC, Canada), which has a density of $0.87 \mathrm{~g} / \mathrm{mL}$. The oils that make up this mixture all come from natural sources (vegetable and tree resins) and 2) Epoxy coating supplied by Composites Envision (Wausau, WI, USA). The epoxy coating was prepared in the laboratory by mixing two parts of epoxy and one part of the hardener. According to the data safety sheets of both products, the epoxy resin is a homopolymer: the diglycidyl ether of bisphenol. At the same time, the hardener is a mixture of substances: the polyetheramine, the nonylphenol, and the 2-piperazine-1-ylethylamine.

\subsection{Composite Manufacturing}

WPCs were manufactured according to a factorial plan where factors are polymer (PLA, PP), fiber type (kraft, TMP, CTMP), and fiber proportion (50, 60, and 70\%) for a total of 18 formulations. The blends were extruded into wood-polymer pellets using a twin-screw extruder (Thermo Scientific HAAKE PolyLab OS Rheodrive 7 with Rheomex OS extruding module, Thermo Electron $\mathrm{GmbH}$, Karlsruhe, Germany). The temperature profile was $160-170-180{ }^{\circ} \mathrm{C}$, and the rotation speed was $70 \mathrm{rpm}$. Then, the pellets were dried for $24 \mathrm{~h}$ at $80^{\circ} \mathrm{C}$. The last step consisted of manufacturing standard test samples using an injection molding machine (Haitian MA600II/130, Ningbo, China). 


\subsection{Surface Treatment and Coating}

The PLA WPCs were mechanically pre-treated with 160 grit abrasive paper, while the PP WPCs were pre-treated with chromic acid. The choice of chromic treatment relies on previous reports, including Oporto et al. [25]. They investigated the effect of chromic treatment on the surface of WPCs made from pine flour and polypropylene. This treatment increased the oxygen content on the surface and showed the highest surface energy values. Mohamed et al. [26] also reported the appearance of new polar groups because of the chromic treatment that improves the wettability and adhesion ability of the wood/PE composites. The chromic sulfuric acid solution was prepared according to the ASTM D2093 standard [27]. Before chromic treatment, WPC specimens were deburred and wiped with acetone. The specimens were placed in a clean, dust-free environment to evaporate solvents or moisture condensation. The surfaces were then sanded with 320 fine-grit sandpaper. The samples were cleaned with high-pressure air to remove dust. These preliminary steps prepared the surface for the chromic treatment. The samples were then immersed in a fresh chromic solution under constant stirring at $70^{\circ} \mathrm{C}$ for $5 \mathrm{~min}$ and then washed with tap water for $3 \mathrm{~min}$ and followed by distilled water for $20 \mathrm{~min}$. Finally, they were dried in an oven at $40^{\circ} \mathrm{C}$ for $1 \mathrm{~h}$ and conditioned in desiccators before coating.

Following the mechanical or chemical treatment, WPC surfaces were coated according to the instructions indicated on the product datasheets. For the acrylic coating, two layers were applied to the WPC surface. The first layer saturated the sample; the second layer was used as a topcoat after $18 \mathrm{~h}$ to even excess oil. The samples were then dried for $24 \mathrm{~h}$. For the epoxy coating, two coats were applied with a drying time of $12 \mathrm{~h}$. Before the 2nd coat, the WPC surface was sanded with 320 grit sandpaper. The composites were dried for $24 \mathrm{~h}$ before testing.

\subsection{Dimensional Stability}

The effect of coatings on water absorption was studied by 1) measuring the contact angle: 3 repetitions were performed for the different mixtures and coating (uncoated, Epoxy coating, and acrylic coating) combinations ( 3 replicates $\times 18$ formulations $\times 3$ types of coatings). According to ASTM D 570 [28], water absorption tests were carried out using $50 \mathrm{~mm}$ diameter specimens. For each formulation, 12 samples were produced (a total of 240) for the different mixtures. Specimen dimensions were measured using a micrometer with an accuracy of $\pm 0.001 \mathrm{~mm}$, while specimens were measured using a laboratory balance with an accuracy of $\pm 0.001 \mathrm{~g}$. The water absorption (Equation (1)) and thickness swell (Equation (2)) were calculated according to the following formulas:

$$
\begin{gathered}
\mathrm{WA}(\%)=\frac{\mathrm{W}_{\mathrm{f}}-\mathrm{W}_{\mathrm{i}}}{\mathrm{W}_{\mathrm{i}}} \times 100 \\
\mathrm{TS}(\%)=\frac{\mathrm{T}_{\mathrm{f}}-\mathrm{T}_{\mathrm{i}}}{\mathrm{T}_{\mathrm{i}}} \times 100
\end{gathered}
$$

WA: Water absorption rate; $\mathrm{W}_{\mathrm{f}}$ : final weight after water immersion (120 min in boiling water); $\mathrm{W}_{\mathrm{i}}$ : initial weight before water immersion; TS: Thickness swell; $\mathrm{T}_{\mathrm{f}}$ : final thickness after water immersion (120 min in boiling water); $\mathrm{T}_{\mathrm{i}}$ : initial thickness before water immersion.

\subsection{Contact Angle Measurement}

A Goniometer (DataPhysics company model OCA 15EC; Filderstadt, Germany) performed contact angle measurements. SCA 26 software analyzed the images and measured the contact angle every second. The average of the first five measurements is reported. Three repetitions were performed for each formulation (18 formulations $\times 3$ treatments (uncoated, acrylic coating and epoxy coating) $\times 3$ repetitions). The contact angle measurement accuracy was $\pm 3^{\circ}$. 


\subsection{Statistical Data Analysis}

The physical properties (thickness swell, water absorption, and contact angle) were subjected to an analysis of variance using the ANOVA procedure and customized factorial model using the IBM SPSS Statistics Software version 27. Studied factors were polymer (PP and PLA), fiber type (kraft, CTMP, and TMP), fiber proportion (0, 50, 60, and 70\%), and coating type (uncoated, acrylic coating, and Epoxy coating). All factors were considered fixed. Effects and differences between means were considered statistically significant at $p<0.05$. We verified the ANOVA assumptions using graphical diagnostics (i.e., residual vs. predicted, distribution of observed values) and Levene test for equal variances. No data transformation was required.

\section{Results and Discussion}

\subsection{Effects of Studied Factors on Dimensional Stability}

The analysis of variance (Table 2) investigated the impact of the studied factors (polymeric matrix, fiber type, fiber proportion, and coating type) and their interactions on the contact angle, thickness swell, and water absorption. The thickness swell, the water absorption, and the contact angle all significantly varied with the changes in the polymeric matrix, the fiber type and proportion, and the coating (Table 2).

Table 2. Analysis of variance, with F-values for the studied factors (Polymer type, fiber type, fiber proportion, coating type, and their interactions), and their significance, for thickness swell, water absorption, and composites contact angle after water immersion.

\begin{tabular}{|c|c|c|c|c|c|}
\hline \multirow{2}{*}{ Source } & \multirow{2}{*}{ DF $^{1}$} & Thickness Swell & Water Absorption & \multicolumn{2}{|c|}{ Contact Angle } \\
\hline & & \multicolumn{2}{|c|}{ F-Value } & DF & F-Value \\
\hline Corrected Model & 71 & $35.2 * *$ & $60.6^{* *}$ & 59 & $93.8^{* *}$ \\
\hline Intercept & 1 & $4821.3^{* *}$ & $5133.4^{* *}$ & 1 & $407875.9^{* *}$ \\
\hline Polymeric Matrix (M) & 1 & $1040.9 * *$ & $475.9 * *$ & 1 & $1244.0 * *$ \\
\hline Fiber Type (F) & 2 & $41.4^{* *}$ & $141.6^{* *}$ & 2 & 10.350 \\
\hline Fiber Proportion (P) & 3 & $47.0 * *$ & $400.8^{* *}$ & 3 & $272.9^{* *}$ \\
\hline Coating $(\mathrm{C})$ & 2 & $323.3^{* *}$ & $447.4^{* *}$ & 2 & $653.9^{* *}$ \\
\hline $\mathbf{M} \times \mathbf{F}$ & 2 & $16.7^{* *}$ & $38.0 * *$ & 2 & $148.9 * *$ \\
\hline $\mathbf{M} \times \mathbf{P}$ & 3 & $8.3^{* *}$ & $21.5^{* *}$ & 3 & $14.2^{* *}$ \\
\hline $\mathbf{M} \times \mathbf{C}$ & 2 & $66.3^{* *}$ & $64.1^{* *}$ & 2 & $8.6^{* *}$ \\
\hline $\mathbf{F} \times \mathbf{P}$ & 6 & $9.1^{* *}$ & $28.3^{* *}$ & 6 & $62.5^{* *}$ \\
\hline $\mathbf{F} \times \mathbf{C}$ & 4 & $9.9^{* *}$ & $32.0^{* *}$ & 4 & $6.4^{* *}$ \\
\hline $\mathbf{P} \times \mathbf{C}$ & 6 & $23.3^{* *}$ & $89.9^{* *}$ & 4 & 1.8 n.s. \\
\hline $\mathbf{M} \times \mathbf{F} \times \mathbf{P}$ & 6 & $3.3^{* *}$ & $18.6^{* *}$ & 6 & $63.8^{* *}$ \\
\hline $\mathbf{M} \times \mathbf{F} \times \mathbf{C}$ & 4 & $9.8^{* *}$ & $8.3^{* *}$ & 4 & $2.3^{* *}$ \\
\hline $\mathbf{M} \times \mathbf{P} \times \mathbf{C}$ & 6 & $6.6^{* *}$ & $8.3^{* *}$ & 4 & $6.2^{* *}$ \\
\hline $\mathbf{F} \times \mathbf{P} \times \mathbf{C}$ & 12 & $2.6^{* *}$ & $7.0 * *$ & 8 & 1.5 n.s. \\
\hline $\mathbf{M} \times \mathbf{F} \times \mathbf{P} \times \mathbf{C}$ & 12 & $2.7^{* *}$ & $5.0 * *$ & 8 & $3.0^{* *}$ \\
\hline Error & 144 & - & - & 120 & - \\
\hline Corrected Total & 215 & - & - & 179 & - \\
\hline Adjusted $\mathbf{R}^{2}$ & - & 0.92 & 0.95 & - & 0.97 \\
\hline
\end{tabular}

$\mathrm{DF}^{1}$ : Degree of freedom; ${ }^{* *}$ : Significant at $\alpha=0.05 ;$ n.s.: Non-Significant at $\alpha=0.05$.

Figures 1-3 clearly show the significant effects of the matrix, fiber type, fiber proportion, and coating type on the studied properties. Considering the variation in fibers properties and polymers' hygroscopicity, and the nature of the two coatings, we expected differences in the response of the measured properties among fibers, proportions, coatings, and significant interactions. Indeed, the effect of almost all interactions on the measured properties was highly significant. 


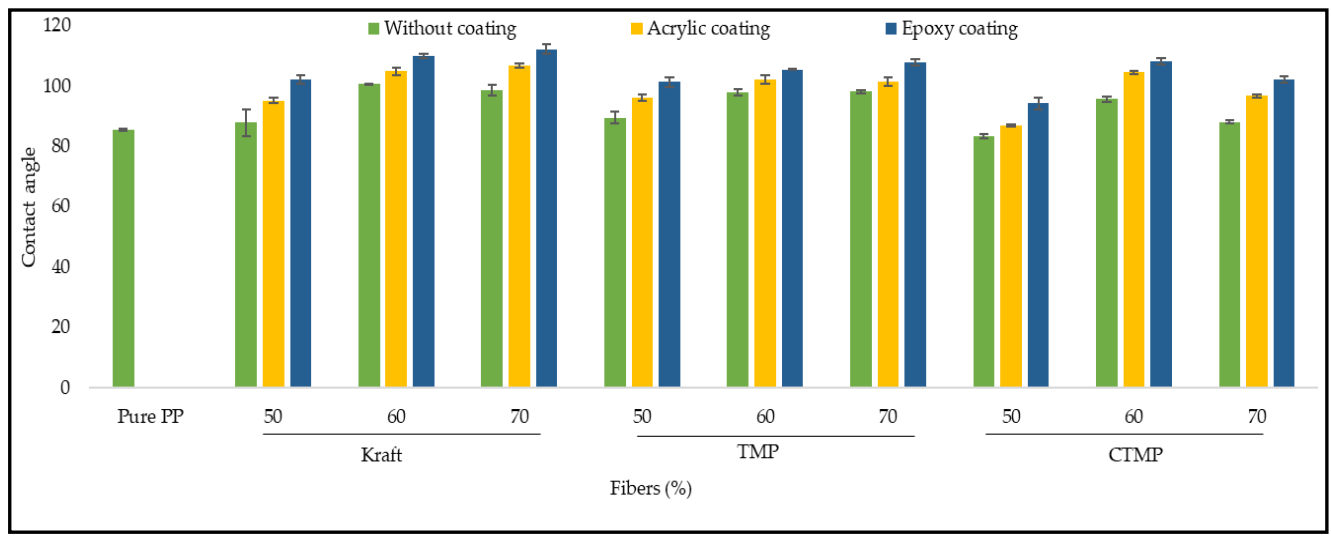

(a)

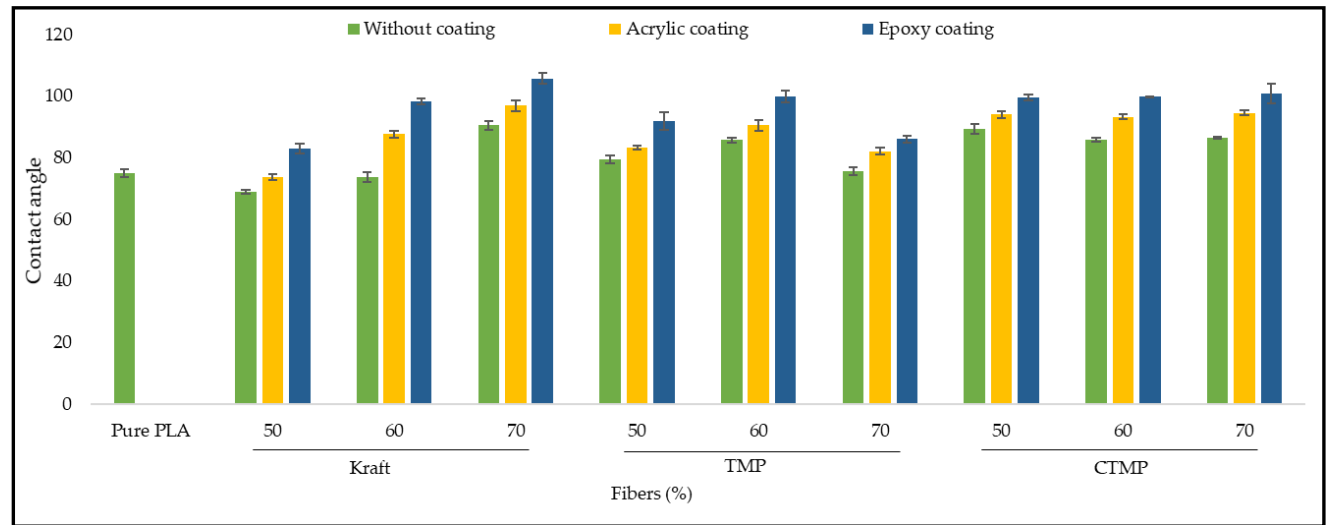

(b)

Figure 1. Contact angle measurements before and after coating. (a) Contact angle of PP-based composites and (b) Contact angle of PLA-based composites.

A significant second-order interaction indicates that the effect of a factor on a property is not the same considering the second factor. For example, a significant matrix $\times$ proportion interaction suggests that the effect of proportion on the properties varies from one matrix to another. The interaction matrix $\times$ fiber $(\mathrm{M} \times \mathrm{F})$ is highly significant for the thickness swelling, water absorption, and contact angle. It suggests that the impact of fiber addition of one fiber type on these properties is different from one matrix to another. Similarly, changing fiber type will have different effects on these properties for PP or PLA matrix. The matrix $\times$ proportion $(\mathrm{M} \times \mathrm{P})$ interaction is also highly significant on thickness swelling, water absorption, and contact angle because the effect of proportion on these properties varies between the PP and PLA matrixes.

The matrix $\times$ coating $(\mathrm{M} \times \mathrm{C})$ interaction effect is also highly significant on the three measured properties (Table 2). It indicates that the effect of the coatings on these properties varies between the PP and PLA matrixes. Similarly, the significant fiber $\times$ coating on the measured properties suggests that the impact of coating type for a specific matrix varies among the three different fibers. The effect of proportion $\times$ coating interaction was not significant on the contact angle. For a specific composite, the effect of the coating is the same regardless of the fiber proportion.

A significant third-order interaction means that the interaction between two factors is different across the levels of the third factor. For example, a significant matrix $\times$ fiber $\times$ proportion interaction implies that the effect of the interaction matrix $\times$ fiber on a property differs from one fiber proportion to another. The third order and higher-order interactions are difficult to interpret. 
Table 2 further indicates a high coefficient of determination $\left(R^{2}\right)$ for each property. Thus, property variation is explained to a high extent by the studied factors and their interactions. For example, for contact angle, an $\mathrm{R}^{2}$ of 0.97 is found. Thus, $97 \%$ of this property variation is due to the effect of the studied factors and their interactions. Only $3 \%$ of the variation is not explained or is attributed to experimental errors.

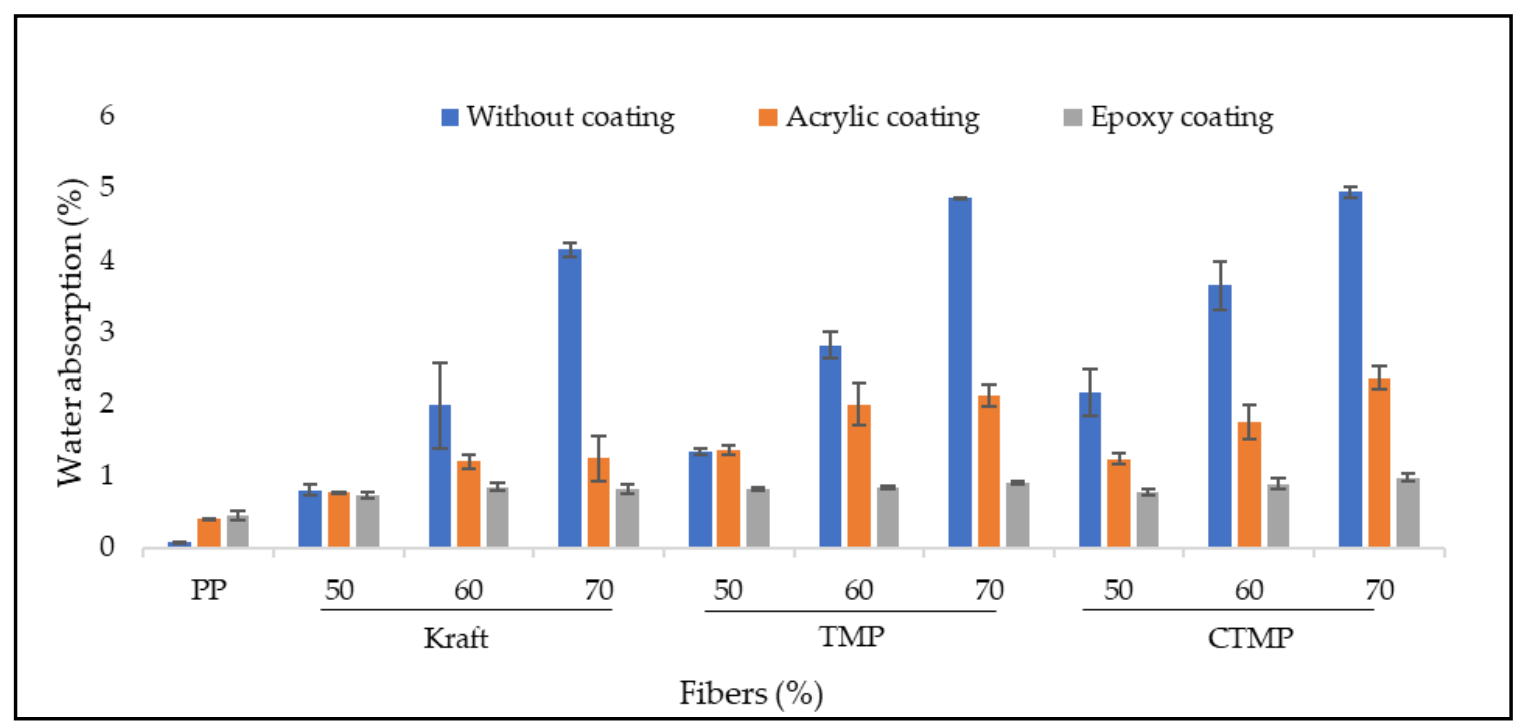

(a)

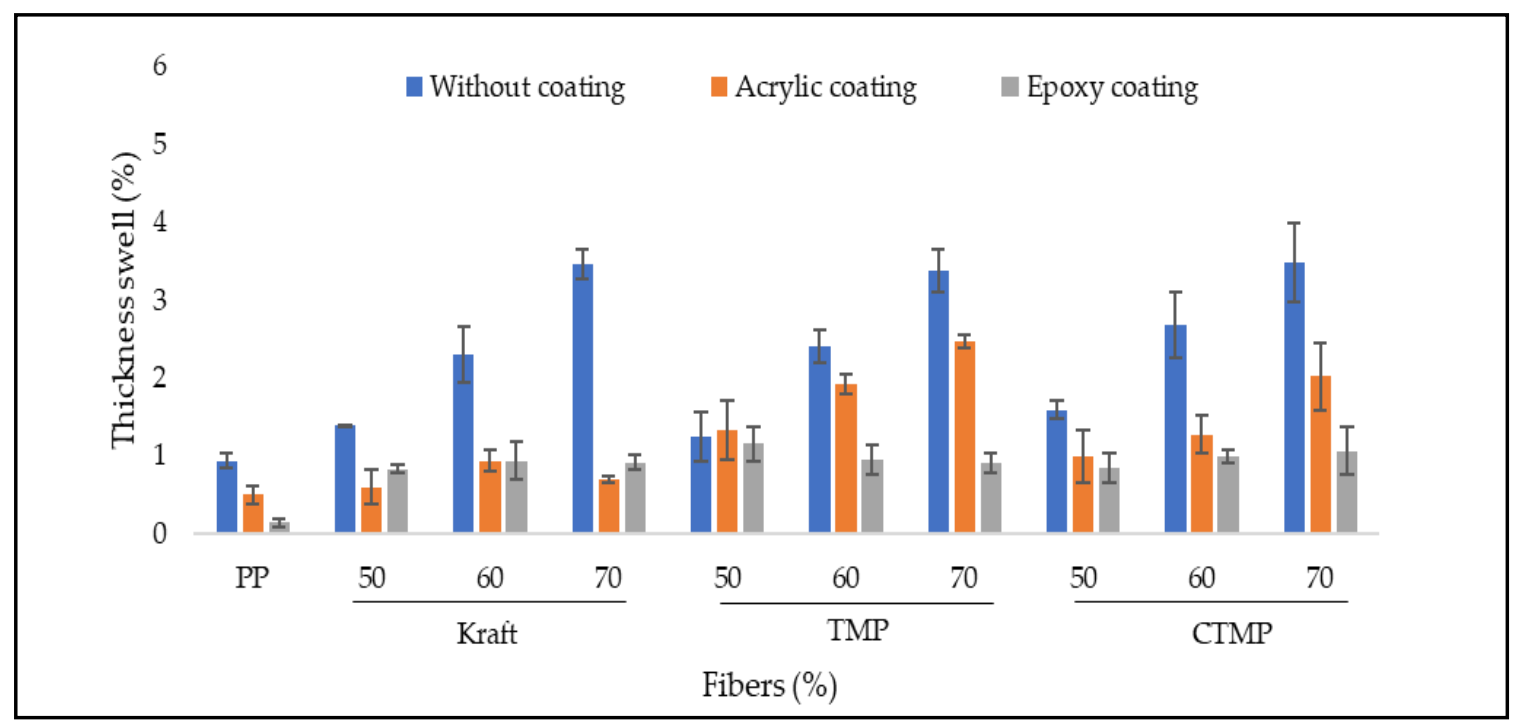

(b)

Figure 2. Comparison of the effect of the two types of coatings on water absorption of polypropylene-based composites: (a) Water absorption evolution and (b) thickness swell evolution.

\subsection{Contact Angle}

Figure 1 shows the results of the contact angle measurements for the different formulations. The trend is the same for PP-based (Figure 1a) and PLA-based composites (Figure 1b). The angle values are slightly higher for composites with a polypropylene matrix, which explains their better resistance to water immersion. However, most composites showed higher contact angles than pure polymers. 


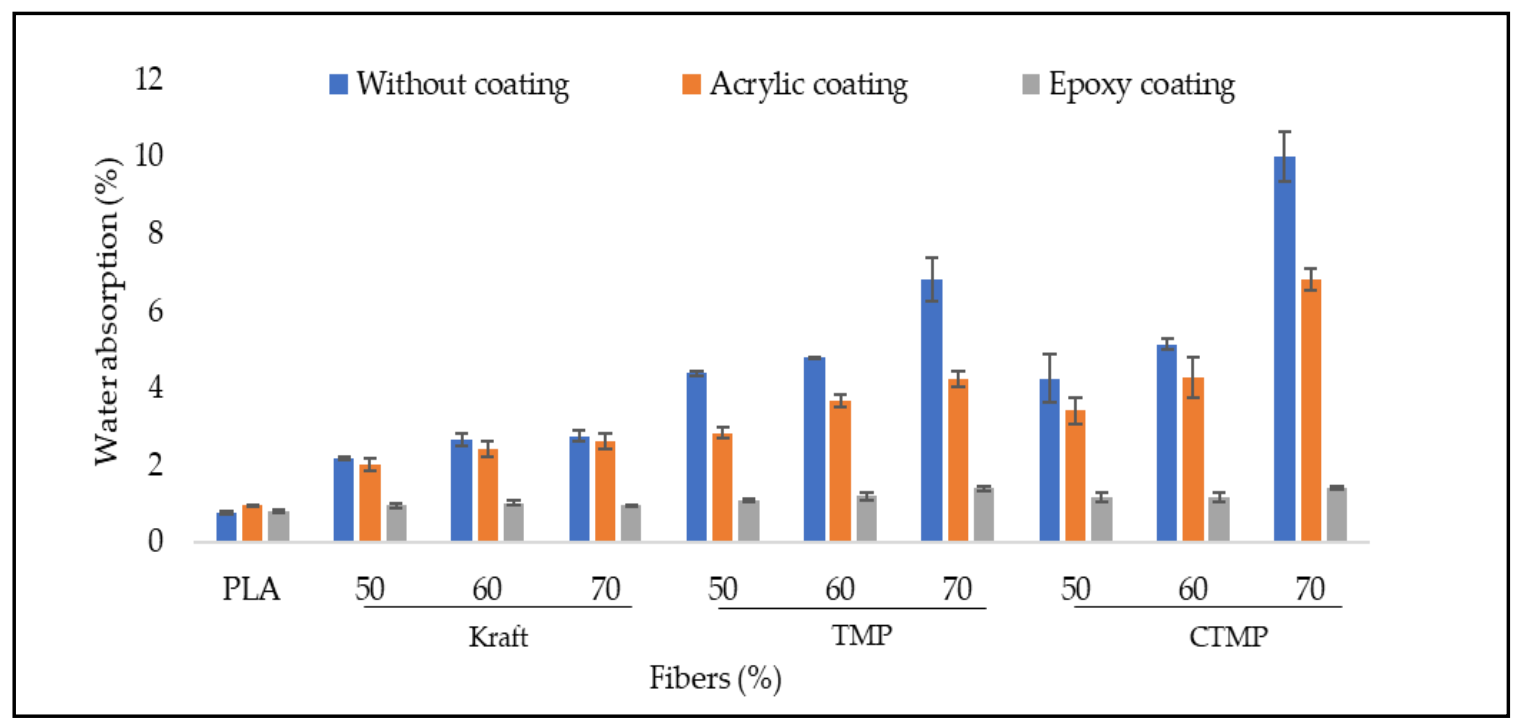

(a)

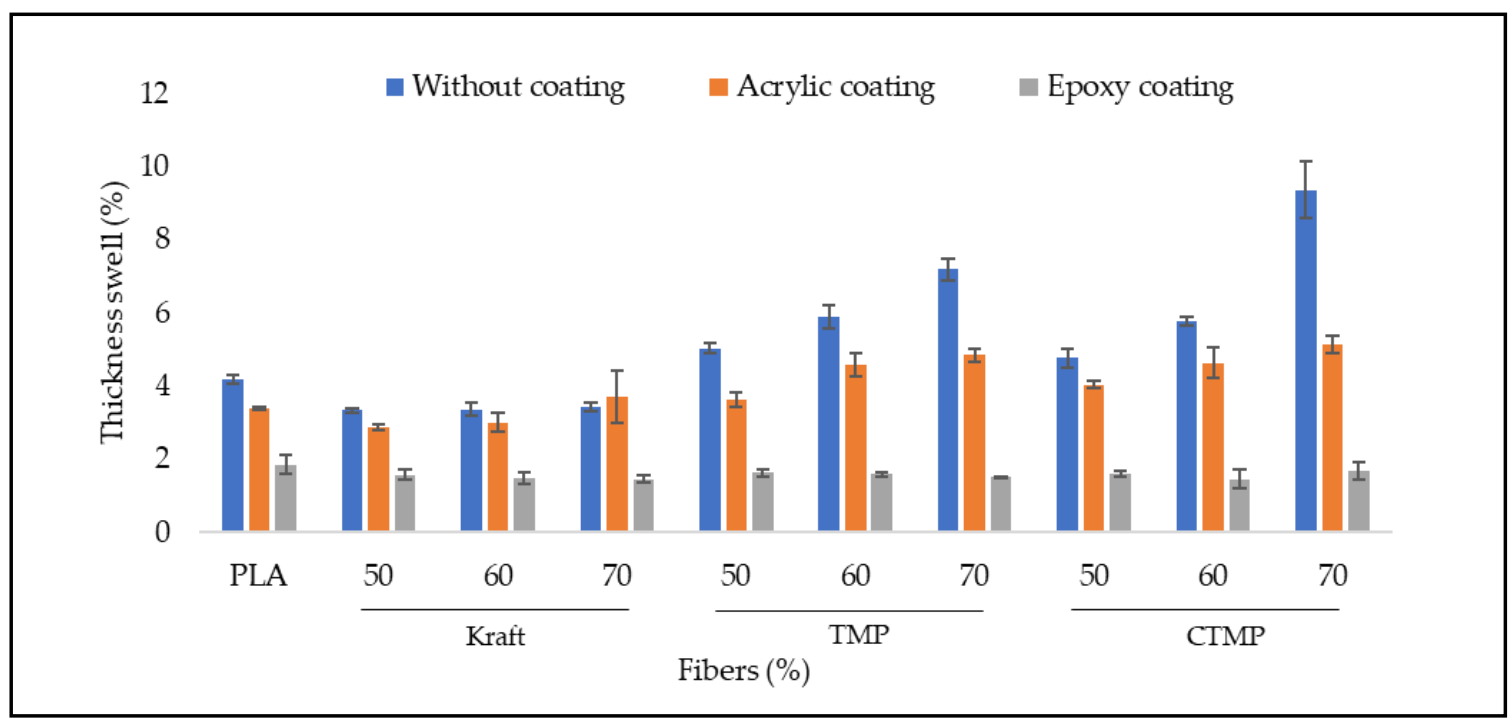

(b)

Figure 3. Comparison of the effect of the two types of coatings on water absorption of polylactic-acid-based composites: (a) Water absorption evolution and (b) thickness swell evolution.

Epoxy-coated composites showed the highest contact angles regardless of the nature or content of the fiber or matrix used, which confirms the effectiveness of this coating in ensuring good dimensional stability.

Ayadi et al. [29] concluded that the addition of biochar in WPCs causes an increase in water absorption and contact angle due to surface roughness and agglomerations of the reinforcement in the composite. The authors reported that biochar-polypropylene composites (BPC) treated at $450{ }^{\circ} \mathrm{C}$ were dimensionally stable after six months of water immersion. The contact angle increased for BPCs prepared with biochar made by rapid pyrolysis at temperatures equal to or above $400{ }^{\circ} \mathrm{C}$. The low water absorption values for BPCs were explained by the physical appearance of biochar and chemical and molecular changes improving its hydrophobicity [29].

Saddem [30] studied the relationship between contact angle and water absorption rate of reinforced composites by acetylated fibers. This study demonstrated that, for the same proportion of wood fibers, composites made with acetylated fibers absorb significantly less water and have a higher contact angle than composites made with untreated fibers. This 
study also investigated acetylation treatment time. WPCs made with treated fibers for $6 \mathrm{~h}$ showed the most significant reduction in water absorption at about $40 \%$ and the highest contact angles compared to those treated for 2 and $4 \mathrm{~h}$.

\subsection{Water Absorption of Uncoated WPCs}

Figures 2 and 3 (in blue) show the water absorption and thickness swell of uncoated WPCs. PP composites were dimensionally more stable than PLA composites. The hygroscopicity of both matrices explains this result. Pure polylactic acid is hydrophilic and absorbs water and swells compared to polypropylene, which is hydrophobic. The hydrophilic nature of PLA allows the creation of hydrogen bonds with water molecules. Adding wood fibers to PLA implies increasing the number of hydrogen bonds and free groups in the fibers and PLA [31].

Fiber nature has a significant effect on water absorption and thickness swell. The composites with fibers containing higher lignin content should present lower water uptake values because of the hydrophobic nature of lignin [19]. Therefore, TMP and CTMP reinforced composites were expected to show lower water uptake values than kraft composites because of their high lignin content. Nevertheless, kraft composites performed better. Kraft WPCs showed the lowest water absorption and thickness swell than TMP and CTMP WPCs even though kraft fibers are rich in cellulose and do not contain lignin, the hydrophobic component of lignocellulosic fibers. The higher crystallinity of kraft fibers compared to TMP and CTMP fibers explains this result. The kraft pulping process dissolves most of the amorphous components of the cell membrane, namely the extractive, lignin, and part of the hemicelluloses. The improvement in fiber crystallinity reduces the composite amorphous zones into which water penetrates [32].

Furthermore, the hydroxyl groups of kraft fibers react better with the coupling agents than fibers containing lignin [33], thus reducing the sites for water. Additionally, kraft fibers have better dispersion in composites. The higher water absorption and thickness swell of TMP and CTMP composites compared to the kraft composites is explained by their higher porosity. TMP and CTMP fibers are rigid and do not collapse during processing, which results in a higher porosity [19]. On the other hand, kraft fibers are flexible and tend to collapse during processing and lead to composites with fewer voids. Espert et al. [19] found similar results, where they found that Coir-filled composites were less sensitive to water absorption due to their high lignin content. TMP composites showed slightly better dimensional stability than CTMP composites. The fiber surface chemistry changes by the wood chip chemical treatment before CTMP pulping make them more hydrophilic. Soucy [33] reported a similar finding for HDPE WPC made with kraft, TMP, and CTMP fibers.

Wood fibers are responsible for the water absorption and thickness swell in WPCs because of their hydrophilic character. For both PP and PLA WPCs, higher fiber content led to a higher amount of water uptake and thickness swell for all tested composites regardless of the nature of the fiber. These results are in good agreement with previous findings $[7,8,13,19,31]$. Lin et al. [34] explained the water absorption phenomenon by different processes: 1 ) diffusion of water molecules inside the micro gaps between polymer chains, 2) capillary transport into the gaps and flaws at the interfaces between fibers and polymer because of incomplete wettability and impregnation, and 3) water transport by microcracks in the matrix formed during the processing.

\subsection{Effect of Coatings on Water Absorption and Thickness Swelling}

Figure 2 shows the water absorption (2a) and thickness swelling $(2 b)$ results for uncoated and coated polypropylene composites with acrylic and Epoxy coatings. In Figure $2 \mathrm{~b}$, the uncoated PP showed higher thickness swelling than the coated PP samples while showing nearly no mass gain. It is possible that the uncoated samples underwent warping upon immersion in boiling water for 120 min without weight gain. The coatings reduced the thickness swell by preserving the structural stability of the sample. The slight mass gain 
observed for the coated PP samples could be explained by the presence of micropores on the coating layer or in the interface where water can be deposited.

The results show that the two coatings improved the composites' dimensional stability but in different ways (Figure 2). Indeed, for most of the formulations, the epoxy coating had provided better composite stabilization. For PP composites filled with $70 \%$ TMP fibers, the thickness swelling is reduced by $30 \%$ with the acrylic coating and $70 \%$ with the epoxy coating. The difference in thickness swelling among proportions for the same type of fiber explains the significant interaction proportion $\times$ coating (Table 2). The water absorption decreased by $55 \%$ and $80 \%$ following acrylic and epoxy coatings, respectively. The improvement in thickness and water absorption for epoxy-coated composites is more remarkable for the same fiber than acrylic-coated composites. The significant interaction fiber $\times$ coating on thickness swell supports this affirmation (Table 2). These results are in good agreement with Mohamed et al. [26], who reported that WPC treated with chromic acid and coated with epoxy achieved lower water absorption than the untreated ones.

Figure 3 shows the variation of water absorption (3a) and thickness swelling ( $3 b$ ) of PLA-based composites. In good agreement with previous findings [35] coated and uncoated PLA samples showed a low water absorption $(<1 \%)$. These low values make it difficult to detect any change in water absorption due to the coating. The thickness swell of PLA is higher than the water absorption in good agreement with a previous report [35]. The action of boiling water, which attacks the bonds, causes deformation, and creates voids, is among the plausible explanations.

Coating improved the moisture resistance of most PLA biocomposites. The epoxy coating led to the best performance where the water absorption and thickness swelling did not exceed $2 \%$. In contrast, for composites coated with acrylic oil, values were up to $6 \%$. The effect of the epoxy coating is greater for composites formed by CTMP fibers. At a content of $70 \%$, the water absorption decreases by up to $80 \%$ compared to uncoated composites.

The two coatings are different. The first acrylic-based coating is a protective oil whose protection system consists of impregnating the composite's surface. The epoxy coating consists of a resin mixture with a hardener, which constitutes a thicker outer plasticizing layer. The nature of each coating would explain the behavior of coated composites concerning water absorption. As stated previously, epoxy-coated composites showed a better resistance to water absorption.

Other than coating, wood thermal and chemical modifications can improve the biocomposite dimensional stability. Ayadi et al. [29] studied the physical properties of WPC and biochar polymer composites (BPC) obtained at different pyro-gasification temperatures and different fiber proportions (30,40, and 50\%). This study showed that higher fiber proportions for both wood and biochar led to greater water uptake and volume change. However, the swelling of wood composites was higher than biochar composites at any fiber proportion. They showed that the composites made of HDPE and 50\% biochar (pyro-gasification temperature of $445^{\circ} \mathrm{C}$ ) reduced the water uptake by up to $75 \%$ compared to wood-filled composites ( $50 \%$ wood $/ 50 \%$ HDPE). Wood fiber acetylation also improved WPC dimensional stability. Increased fiber proportion increased swelling and water absorption for WPC made of both acetylated and untreated wood fibers [30].

\subsection{Contact Angle-Water Absorption Relationship}

The contact angle increases when the water absorption decreases (Figure 4). Composites with the lowest fiber content showed the smallest water absorption values (Figure 4a). The composites charged with $50 \%$ fiber performed better in the presence of water. However, higher contact angles were found for composites filled with 60 and $70 \%$ fibers. This trend may be explained by the surface roughness, which is more important in composites with high fiber content. This relationship is also affected by the nature of the fiber. Figure $4 \mathrm{~b}$ shows that composites filled with kraft fiber absorbed less water and presented the highest values for contact angle compared to CTMP and TMP fillers. Figure 4c illustrates the 
relationship between water absorption and contact angle concerning the type of matrix used. The PP-based composites performed better than the PLA composites.

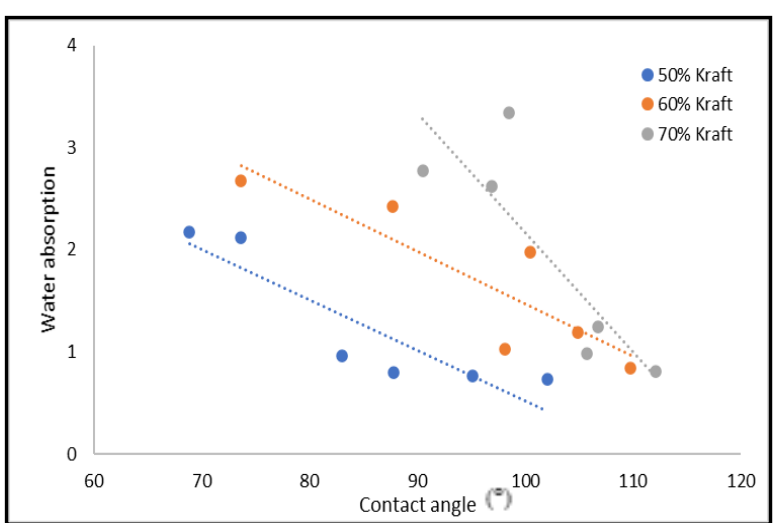

(a)

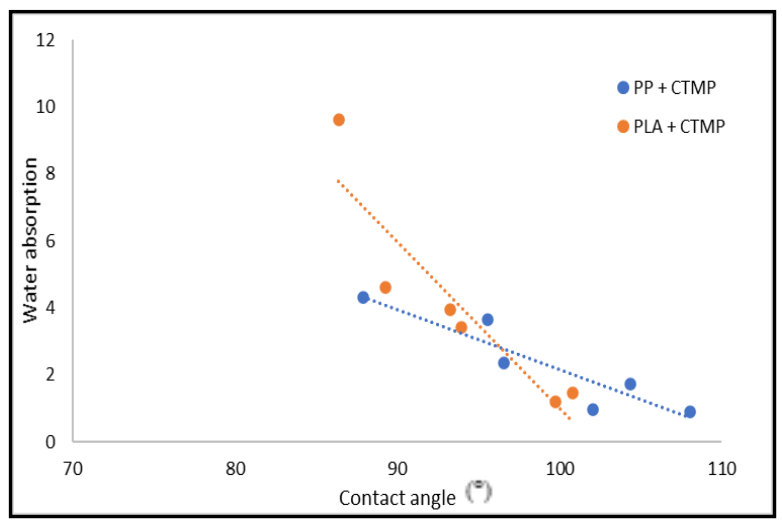

(c)

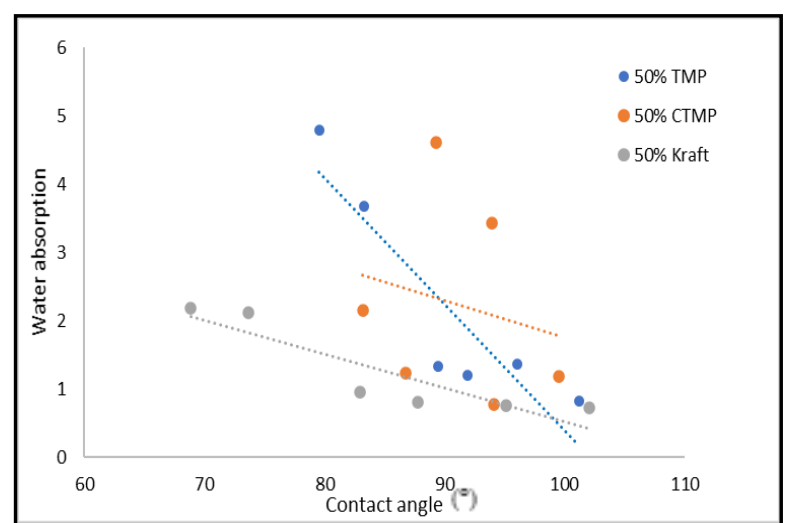

(b)

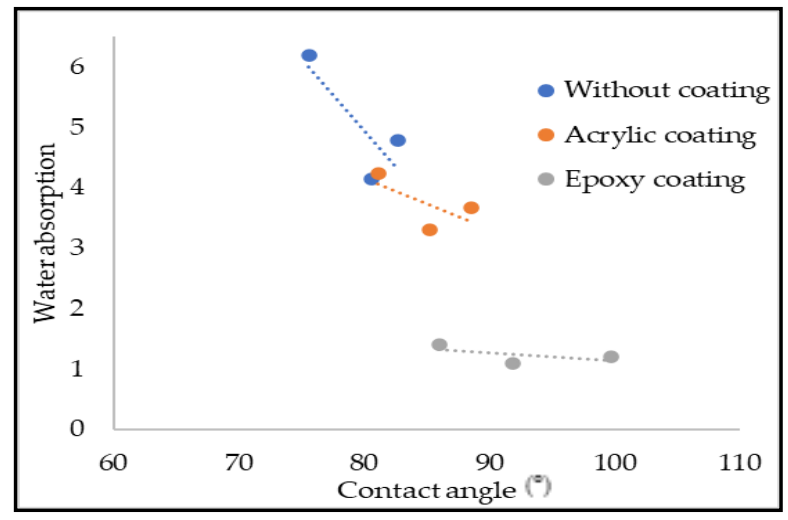

(d)

Figure 4. Relationship between water absorption and contact angle for composites made with (a) Kraft and different fiber content (50-70\%); (b) filled with 50\% of different fiber type (kraft, TMP, and CTMP); (c) CTMP with different matrixes (PP, PLA), and (d) coated and uncoated TMP-PLA biocomposites at 50, 60, and 70\% proportions.

Results presented in Figure $4 \mathrm{~d}$ confirm that both coatings improved the resistance of composites to water absorption. The epoxy performed better than acrylic. For the epoxy coated WPC, contact angles were high and the water absorption very low with almost no variation with fiber proportion. However, negative relationship trends are found between contact angle and water absorption for uncoated and acrylic coated composites.

\section{Conclusions}

The fiber type and content, the matrix, and the coating have significant effects on the dimensional stability of composites. For both matrices, increasing fiber content led to an increase in WPC water absorption and thickness swelling. These increases depended on the nature of the fiber. Kraft fiber gave the best dimensional stability compared to TMP and CTMP fibers. PLA composites were less resistant to moisture than PP composites.

Both coatings significantly reduced the composites' water absorption and thickness swelling compared to uncoated composites. The contact angle of coated WPCs was higher than the uncoated ones, indicating an improvement in their hydrophobicity. The epoxy coating acted as a protective film that prevented water penetration. This coating was more effective than acrylic coating and significantly reduced the water absorption and the thickness swell for all formulations. 
Author Contributions: Conceptualization, A.K., M.R. and S.M.; methodology, M.R.; formal analysis, M.R., F.E.; investigation, M.R.; resources, A.K.; data curation, M.R., F.E. and A.K.; writing-original draft preparation, M.R. and F.E.; writing-review and editing, A.K., F.G., H.M. and M.K.; supervision, A.K., F.G., M.K. and H.M.; project administration, A.K.; funding acquisition, A.K., F.G. and S.M. All authors have read and agreed to the published version of the manuscript.

Funding: This research was funded by the Canada Research Chair Program, grant number 557752, NSERC 567663, CRIBIQ, 2015-29-C18, MITACS, IT08227.

Institutional Review Board Statement: Not applicable.

Informed Consent Statement: Not applicable.

Data Availability Statement: The data presented in this study are available on request from the corresponding author. The data are not publicly available because they are still being used for modeling work.

Acknowledgments: The authors would like to thank William Belhadef and Gilles Villeneuve for technical assistance, the CTRI for assisting in contact angle measurements, and Sebastien Migneault for scientific and technical support.

Conflicts of Interest: The authors declare no conflict of interest.

\section{References}

1. Rajak, D.K.; Pagar, D.D.; Kumar, R.; Pruncu, C.I. Recent progress of reinforcement materials: A comprehensive overview of composite materials. J. Mater. Res. Technol. 2019, 8, 6354-6374. [CrossRef]

2. Vasiliev, V.V.; Morozov, E.V. Introduction in Advanced Mechanics of Composite Materials and Structures, 4th ed.; Elsevier: Amsterdam, The Netherlands, 2018; pp. 17-25.

3. Market Analysis Report. Available online: https://www.grandviewresearch.com/industry-analysis/wood-plastic-compositesmarket (accessed on 25 November 2020).

4. Adhikary, K.B.; Pang, S.; Staiger, M.P. Long-term moisture absorption and thickness swelling behaviour of recycled thermoplastics reinforced with Pinus radiata sawdust. Chem. Eng. J. 2008, 142, 190-198. [CrossRef]

5. Ratanawilai, T.; Tanner, K. Alternative polymeric matrices for wood-plastic composites: Effects on mechanical properties and resistance to natural weathering. Constr. Build. Mater. 2018, 172, 349-357. [CrossRef]

6. Bledzki, A.K.; Jaszkiewicz, A.; Scherzer, D. Mechanical properties of PLA composites with man-made cellulose and abaca fibres. Compos. Part A Appl. Sci. Manuf. 2009, 40, 404-412. [CrossRef]

7. Migneault, S.; Koubaa, A.; Erchiqui, F.; Chaala, A.; Englund, K.; Krause, C.; Wolcott, M. Effect of fiber length on processing and properties of extruded wood-fiber/HDPE composites. J. Appl. Polym. Sci. 2008, 110, 1085-1092. [CrossRef]

8. Soucy, J.; Koubaa, A.; Migneault, S.; Riedl, B. The potential of paper mill sludge for wood-plastic composites. Ind. Crop. Prod. 2014, 54, 248-256. [CrossRef]

9. Bledzki, A.K.; Gassan, J.; Theis, S. Wood-filled thermoplastic composites. Mech. Compos. Mater. 1998, 34, 563-568. [CrossRef]

10. Ashori, A. Wood-plastic composites as promising green-composites for automotive industries! Bioresour. Technol. 2008, 99, 4661-4667. [CrossRef] [PubMed]

11. Mu, T.; Liu, L.; Lan, X.; Liu, Y.; Leng, J. Shape memory polymers for composites. Compos. Sci. Technol. 2018, 160, 169-198. [CrossRef]

12. Arbelaiz, A.; Mondragon, I. Testing the effect of processing and surface treatment on the interfacial adhesion of single fibres in natural fibre composites. In Interface Engineering of Natural Fibre Composites for Maximum Performance; Elsevier: Amsterdam, The Netherlands, 2011; pp. 146-185.

13. Dhakal, H.N.; Zhang, Z.Y.; Richardson, M.O.W. Effect of water absorption on the mechanical properties of hemp fibre rein-forced unsaturated polyester composites. Compos. Sci. Technol. 2006, 67, 1674-1683. [CrossRef]

14. Beg, M.; Pickering, K. Accelerated weathering of unbleached and bleached Kraft wood fibre reinforced polypropylene composites. Polym. Degrad. Stab. 2008, 93, 1939-1946. [CrossRef]

15. Fang, H.; Zhang, Y.; Deng, J.; Rodrigue, D. Effect of fiber treatment on the water absorption and mechanical properties of hemp fiber/polyethylene composites. J. Appl. Polym. Sci. 2013, 127, 942-949. [CrossRef]

16. Migneault, S.; Koubaa, A.; Perré, P.; Riedl, B. Effects of wood fiber surface chemistry on strength of wood-plastic composites. Appl. Surf. Sci. 2015, 343, 11-18. [CrossRef]

17. Célino, A.; Fréour, S.; Jacquemin, F.; Casari, P. The hygroscopic behavior of plant fibers: A review. Front. Chem. 2014, 1, 1-12. [CrossRef]

18. Karmaker, A.C. Effect of water absorption on dimensional stability and impact energy of jute fibre reinforced polypropylene. J. Mater. Sci. Lett. 1997, 16, 462-464. [CrossRef] 
19. Espert, A.; Vilaplana, F.; Karlsson, S. Comparison of water absorption in natural cellulosic fibres from wood and one-year crops in polypropylene composites and its influence on their mechanical properties. Compos. Part A Appl. Sci. Manuf. 2004, 35, 1267-1276. [CrossRef]

20. Heinemann, M.; Fritz, H.G. Polylactid-Struktur, Eigenschaften and Anwendungen. In Proceedings of the 19th Stuttgater, Plastic Congress, Stuttgart, Germany, 8-10 March 2005.

21. Teng, X.L.; Di, M.W. Effect of liquid oxidation surface treatment on bonding properties of wood/polyethylene composites. In Applied Mechanics and Materials; Trans Tech Publication: Stäfa, Switzerland, 2011.

22. Maria Irudaya Raj, L.; Sathishkumar, J.; Kumaragurubaran, B.; Gopal, P. Analysis of Hard Chromium Coating Defects and its Prevention Methods. Int. J. Eng. Adv. Technol. (IJEAT) 2013, 2, 427-432.

23. Bielicka, A.; Bojanowska, I.; Wisniewski, A. Two faces of chromium - Pollutant and bioelement. Pol. J. Environ. Stud. 2005, 14, 5-10.

24. Sneddon, C. Chromium and its negative effects on the environment. Geology and Human Health course. Montana State University, Bozeman, MT, USA. 2012. Available online: https://serc.carleton.edu/NAGTWorkshops/health/case_studies/ chromium.html (accessed on 1 June 2021).

25. Oporto, G.S.; Gardner, D.J.; Bernhardt, G.; Neivandt, D.J. Characterizing the mechanism of improved adhesion of modified wood plastic composite (WPC) surfaces. J. Adhes. Sci. Technol. 2007, 21, 1097-1116. [CrossRef]

26. Mohamed, M.R.; Naguib, H.; El-Ghazawy, R.A.; Shaker, N.O.; Amer, A.A.; Soliman, A.M.; Kandil, U.F. Surface Activation of Wood Plastic Composites (WPC) for Enhanced Adhesion with Epoxy Coating. Mater. Perform. Charact. 2019, 8, 22-40. [CrossRef]

27. ASTM D2093-03. Standard Practice for Preparation of Surfaces of Plastics Prior to Adhesive Bonding; ASTM International: West Conshohocken, PA, USA, 2017. Available online: https:/ / www.astm.org/Standards/D2093.htm (accessed on 20 November 2020).

28. ASTM D570-98. Standard Test Method for Water Absorption of Plastics; ASTM International: West Conshohocken, PA, USA, 2018. Available online: https:/ / www.astm.org/Standards/D570 (accessed on 20 November 2020).

29. Ayadi, R.; Koubaa, A.; Braghiroli, F.; Migneault, S.; Wang, H.; Bradai, C. Effect of the Pyro-Gasification Temperature of Wood on the Physical and Mechanical Properties of Biochar-Polymer Biocomposites. Materials 2020, 13, 1327. [CrossRef] [PubMed]

30. Saddem, M. Étude des Effets de la Variabilité de la Fibre et de la Matrice sur les Propriétés des Composites bois Polymère. Ph.D. Thesis, Université du Québec en Abitibi-Témiscamingue, Rouyn-Noranda, QC, Canada, 2017. Available online: https: / / depositum.uqat.ca/id/eprint/726/1/Saddem\%2C\%20Mourad.pdf (accessed on 12 December 2020).

31. Ndazi, B.; Karlsson, S. Characterization of hydrolytic degradation of polylactic acid/rice hulls composites in water at different temperatures. Express Polym. Lett. 2011, 5, 119-131. [CrossRef]

32. Bouafif, H.; Koubaa, A.; Perré, P.; Cloutier, A. Effects of fiber characteristics on the physical and mechanical properties of wood plastic composites. Compos. Part A Appl. Sci. Manuf. 2009, 40, 1975-1981. [CrossRef]

33. Soucy, J. Potentiel d'utilisation des Fibres de Papier dans la Conception de Composites bois Polymères par une Technique D'extrusion. Master's Thesis, Université du Québec en Abitibi-Témiscamingue, Rouyn-Noranda, QC, Canada, 2007. Available online: https://depositum.uqat.ca/id/eprint/125/1/joelsoucy.pdf (accessed on 12 December 2020).

34. Lin, Q.; Zhou, X.; Dai, G. Effect of hydrothermal environment on moisture absorption and mechanical properties of wood flour-filled polypropylene composites. J. Appl. Polym. Sci. 2002, 85, 2824-2832. [CrossRef]

35. Sherwani1, S.F.K.; Sapuan, S.M.; Leman, Z.; Zainudin, E.S.; Khalina, A.; Ilyas, R.A.; Syafi, R. Water Absorption Behaviour and Diffusion Coefficient of Sugar Palm Fibre-Reinforced Polylactic Acid Composites. In Proceedings of the 7th Postgraduate Seminar on Natural Fibre Reinforced Polymer Composites, Selangor, Malaysia, November 2020; pp. 10-1246. 